demonstrate the superiority of the method in diagnosis

Spatiocardiography is the simultaneous display of $x, y$ and $z$ co-ordinates on the face of a single cathode ray tube. The $y$ co-ordinate is displayed on the horizontal axis of the tube face, while the $x$ and $z$ co-ordinates are shown on the vertical axis. This is achieved by switching the electron beam rapidly between $x$ and $x+z$. The switching frequency provides a time scale. This ingenious solution is cheap and provides synchronous loops in two planes.

The application of the inverse square law, the importance of orthogonal placing of the electrodes and the method of determining the electrical centre of the heart (E.C.H.) are all explained. The placement of electrodes is by measurement, and amplifier gain is adjusted to allow for distance from the E.C.H., the position of which is assumed for routine use.

Spatiocardiography, even for routine use, is a more time consuming method than conventional scalar electrocardiography and it is doubtful if it would be of more clinical use at the present time. Nevertheless techniques of this kind lend themselves to much more precise quantitative analysis and will come to be used routinely. Meanwhile the theoretical aspects of these methods cannot but add to our understanding of scalar electrocardiography.

\section{Tonometry and Tonography}

J. Gloster. Pp. xi +191 , illustrated. London: J. \& A. Churchill. 1966. 40s.

Tonometry and tonography afford a means of measuring the intraocular pressure and deriving an estimate of the outflow of aqueous humour from successive measurements. Of necessity a considerable mathematical theory has evolved in the development of these procedures to their present level of refinement. Dr. Gloster unfolds this theory step by step in an admirably lucid fashion, presenting a nice balance between attention to detail and didactic exposition. He also relates this theory to practice and discusses the value of these investigations in the diagnosis and management of primary glaucoma, particularly chronic simple glaucoma.

Impression tonometry, using the weighted Schiotz instrument is discussed and the related theory unfolded step by step, $\mathrm{Pt}$ values, $\mathrm{K}$, the coefficient of ocular rigidity, and finally Po values. Applanation tonometry is discussed with special reference to the Goldmann instrument. The clinical determination of ocular rigidity is considered, and theory and practical application of the Friedenwald nomogram explained. This section of the book concludes with a discussion of the normal intraocular pressure. Later chapters deal with tonography and include a sober estimate of its practical value.

This monograph is born of a thorough mastery of the subject from the theoretical and clinical aspects, and it is this comprehensive view which is so valuable, dispelling the mystery and infallibility of these measurements, and making them useful tools whose characteristics are clearly understood. The book is warmly recommended by a clinician to his colleagues if they, like him, find their elementary mathematics failing under the strain when they attempt to master the theory of tonometry and tonography. The fundamental message is that, as with all other special investigations, the results must be interpreted in the context of the clinical examination, as evidence to be weighed, not a revelation of truth.

\section{NEW EDITIONS}

\section{The Care of the Newly Boru Infant}

W. S. Craig and others. 3rd Edition. Pp. viii +666 , illustrated. London and Edinburgh:

E. and S. Livingstone. 1965. 55s.

This is the third edition of this well known book that has emerged from Leeds. It is not stated that it is intended for any particular group of readers although it would seem that the student midwife has much to gain from the text. This fact should not detract in any way from the more general appeal that it will undoubtedly enjoy, since it is comprehensive in scope and is excellently illustrated with over 300 figures. Much attention has been given to the nursing techniques necessary for this very specialised subject, and this is a reflection of the nursing representation among the collaborative authors.

The subject matter is not confined to the normal but attention is also given to congenital abnormalities, infections and neonatal emergencies, with helpful sections on their immediate management.

Some criticisms must be made, in particular the initial chapter entitled 'The Challenge', which failed utterly to stimulate the reviewer, as did the four posed illustrations in it depicting the several unifornied and hatted ladies that the newly born encounters in Leeds. The chapter on Mothercraft, complete with illustrations of posters for the walls of the centre, was also uninspiring.

In spite of these few shortcomings, this book offers excellent value and is to be recommended

\section{Bailey's Textbook of Histology}

Pp. xiii +679 illustrated. Edinburgh and

London: E. \& S. Livingstone. 1965. £5 8s. ్ㅡㅇ

This American textbook of normal histology originally published in 1904, has been brought fully up-to-date by the first revision since 1958. It justly claims to include the new methods of electron microscopy, histochemical and immunohistological techniques and autoradiographic and X-ray diffraction studies. At first sight all this, together with over 600 references, is rather overwhelming in a book "primarily for students rather than a source book for teachers and specialists". However, in reality, the normal cellular structure of the human body, with some comparative anatomy included where appropriate, is simply and clearly set out in an easily readable way. Everywhere structure is related to function. In the words of the author-"The cell is not only a unit of structure but also of physiological activity". "The structures seen under the microscope assume a meaning only in the light of their functional significance". (A surprise in a book that, for example, gives a brief but perfectly adequate account of the modern theories of renal tubular function is the omission of any reference to the alveolar lining layer). There is no undue pre-occupation with the minutiae of technique. Modern methods are skilfully used to explain the appearances seen under the conventional light microscope and to reveal the meaning of cellular physiology. The book is well produced and lavishly illustrated-the electron micrographs are of superb quality. It is highly recommended as a basic medical scientific text of quality. Erratum: Vol. 42 no 487 page 333 (May 1966). The price of 'A Diagnostic Approach to Chest Diseases' by Lillington and Jamplis was incorrectly quoted as £6 16s. It is £5 16s. 